\title{
Severe Accident Simulation of the Laguna Verde Nuclear Power Plant
}

\author{
Gilberto Espinosa-Paredes, ${ }^{1}$ Raúl Camargo-Camargo, ${ }^{2}$ and Alejandro Nuñez-Carrera ${ }^{1}$ \\ ${ }^{1}$ Área de Ingeniería en Recursos Energéticos, Universidad Autónoma Metropolitana-Iztapalapa, \\ Avenida San Rafael Atlixco 186 Col. Vicentina, 09340 Mexico City, DF, Mexico \\ ${ }^{2}$ Nuclear Safety Division, Comisión Nacional de Seguridad Nuclear y Salvaguardias, Doctor Barragán 779, Col. Narvarte, \\ 03020 Mèxico City, DF, Mexico
}

Correspondence should be addressed to Alejandro Nuñez-Carrera, anunezc@cnsns.gob.mx

Received 30 December 2011; Revised 13 March 2012; Accepted 30 March 2012

Academic Editor: Jun Sugimoto

Copyright (C) 2012 Gilberto Espinosa-Paredes et al. This is an open access article distributed under the Creative Commons Attribution License, which permits unrestricted use, distribution, and reproduction in any medium, provided the original work is properly cited.

\begin{abstract}
The loss-of-coolant accident (LOCA) simulation in the boiling water reactor (BWR) of Laguna Verde Nuclear Power Plant (LVNPP) at 105\% of rated power is analyzed in this work. The LVNPP model was developed using RELAP/SCDAPSIM code. The lack of cooling water after the LOCA gets to the LVNPP to melting of the core that exceeds the design basis of the nuclear power plant (NPP) sufficiently to cause failure of structures, materials, and systems that are needed to ensure proper cooling of the reactor core by normal means. Faced with a severe accident, the first response is to maintain the reactor core cooling by any means available, but in order to carry out such an attempt is necessary to understand fully the progression of core damage, since such action has effects that may be decisive in accident progression. The simulation considers a LOCA in the recirculation loop of the reactor with and without cooling water injection. During the progression of core damage, we analyze the cooling water injection at different times and the results show that there are significant differences in the level of core damage and hydrogen production, among other variables analyzed such as maximum surface temperature, fission products released, and debris bed height.
\end{abstract}

\section{Introduction}

Currently Laguna Verde Nuclear Power Plant (LVNPP) uses, for decision-making in emergency case, the Emergency Operating Procedures Guides (EOPG) in order to ensure safe operation and prevent serious consequence in case of possible accident. However, the EOPG does not include the stage of core damage and currently, for the specific case of the LVNPP, there is not a clear definition about the develop of specific guidelines for the management of the severe accident.

LVNPP has two units and is located on the coast of the Gulf of Mexico in the municipality of Alto Lucero in the state of Veracruz. Both units of this plant have a boiling water reactor nuclear steam supply system as designed and supplied by the General Electric Company and designated as BWR 5 .

The primary containment is part of the overall containment system, which provides the capability to reliably limit the release of radioactive materials to the environs subsequent to the occurrence of the postulated Loss-ofcoolant accident (LOCA) so that offsite doses are below the reference values stated in Title 10 of the United States Code of Federal Regulations, Part 50 [1]. The design employs the drywell/pressure-suppression features of the BWR/Mark II containment concept [2].

The Unit 1 started operation in 1990 and the Unit 2 in 1995 with rated power levels of 1931 MWt each. The Unit 1 has been operated with a capacity factor of $80.73 \%$ and the Unit 2 with $85.34 \%$, and this NPP contributes with the $4 \%$ of the national electricity production. This NPP utilizes a single-cycle forced circulation BWR provided by General Electric (GE). LVNPP was originally designed to operate at a gross electrical power output of approximately 695 MWe and a net electrical power output of approximately $674 \mathrm{MWe}$.

The thermal power was uprated by $5 \%$ (from $1931 \mathrm{MWt}$ to $2027 \mathrm{MWt}$ ) during cycle 7 for unit 1 and cycle 4 for unit 2 . In December of 1999, both units were authorized to operate 
to power uprate conditions. In July of 2008, the Comisión Federal de Electricidad (CFE, Mexican Electric Power Company) submitted the applications to the Mexican Regulatory Authority (CNSNS) for an operating license at power level of $2317 \mathrm{MWt}$. This corresponds to $120 \%$ of the original licensed thermal power (OLTP). This approach is referred as constant pressure power uprate (CPPU) because there are no changes in reactor dome pressure for this extended power uprate (EPU).

The BWR are designed with structures, systems, and components (SSCs) to accommodate steam flow rate at least $5 \%$ above the original rating. Safety analysis using better computer codes, methodologies, and operation experience allow the increase the thermal power by $5 \%$ without any hardware modification in the nuclear steam supply system (NSSS). However, the power increases up to $20 \%$ involve major changes in the SSC. Changes in the main condenser, turbine blades, main generator, steam reheater, and booster pump with more capacity are some of the most important changes performed in LVNPP.

In nuclear safety, defense in depth concept should consider accident conditions beyond design basis (severe accidents), although these are highly unlikely, and such conditions have not been explicitly addressed in the original design current nuclear power plants.

An important part of mitigating the damage to the core is the cooling of the debris produced during the melting of the core, but so far not known with certainty at what point should be the cooling by any of the emergency systems and whether it is appropriate to do so. Then, the aim of this work is to present numerical experiments in transient conditions to analyze the behavior of progression of core damage, and consequences such as hydrogen generation and fission products released: (1) without coolant injection in the core region and (2) three different times of the coolant injection with the high-pressure core spray (HPCS) during scenario of a LOCA. The LVNPP model was developed using RELAP/SCDAPSIM code [3-5].

At least until 2003, RELAP/SCDAPSIM [3-5], MELCOR [6], and MAAP4 [7] have been considered as three representative U.S. computer codes that are being widely used for the integral analysis of the core melt accident progression [8]. In this work, we used the RELAP/SCDAPSIM computer code for the analysis of the core and lower plenum phenomena in the simulation of the postulated accident LOCA with and without cooling in LVNPP. RELAP/SCDAPSIM considers the core and vessel with two-dimensional model both axial and radial directions.

\section{System Description}

In order to understand the phenomena of the thermohydraulics process during a hypothetical LOCA with core damage, we presented a brief description of a BWR, where Figure 1 shows the schematic diagram [9].

The reactor water recirculation system (circulates the required coolant flow through the reactor core) consists of two external loops to the reactor vessel. The jet pumps located within the reactor vessel provide a continuous internal circulation path for a major portion of the core coolant flow. The recirculation pumps take the coolant suction from the downward flow in the annulus between the core shroud and the vessel wall. This flow is discharged into the lower core plenum from jet pumps. The coolant water passes along the individual fuel rods inside the fuel channel where it boils and becomes a two-phase steam/water mixture. In the core, the two-phase fluid generates upward flows through the axial steam separators while the steam continues through the dryers and flows directly out through the steam lines into the turbine generator.

The LOCA is postulated as rupture in the suction of the recirculation pipe as is illustrated in Figure 1, in this figure can be observed that the emergency cooling systems: high-pressure core spray system (HPCS), low pressure spray system (LPCS), and low-pressure coolant injection system (LPCI) that inject in the upper plenum.

\section{Preliminaries}

A severe accident is one that exceeds the design basis of the plant sufficiently to cause failure of structures, materials, systems, and so forth, without which it can ensure proper cooling of the reactor core by normal means [10]. Faced with a severe accident the first response is to try to maintain the core cooling by any means available, but in order to carry out such an effort, the response is understand necessary the progression of core damage, because such action has effects that may be determinants in the progression of the accident.

Due to that the severe accident phenomenology is very broad and not all aspects can be studied with a computer code of analysis of the core damage [8]. Then, the information presented in this paper is focused on the study of the progression of core damage phenomena called "In-Vessel". These phenomena are dominated primarily by the temperature, which increases significantly in the absence of coolant flow. Figure 2 shows the progression of core damage for a BWR reactor as a function of temperature [11].

The overheating in the fuel due to lack of cooling, the decay heat, and the chemical reaction between the zirconium and steam, in about an hour, start to discover the fuel, causing the temperature in the center of the core can reach high values, such as 2000 at $2600^{\circ} \mathrm{C}$, so the core begins to melt. With the LOCA scenario, these processes are observed and analyzed in this work.

The molten material will flow slowly down by gravity effects into the lower regions, and colder of the core region, where it resolidifies and blocks the channels between the fuel rods. By this mechanism, a block of solidified material (basin-shaped) of the core (corium) is formed, which collects the molten material. When a sufficient amount of molten material is collected, it will flow to the bottom of the reactor vessel. After a certain time (greater than 30 minutes), the amount of molten corium has flowed to the bottom of the vessel which may correspond to about two thirds of the fuel material from the core region. The rest of the combustible material overheats more slowly and may take several hours to melt. Finally, if the molten material of the core cannot cool due to the loss of geometric and failure of the cooling 


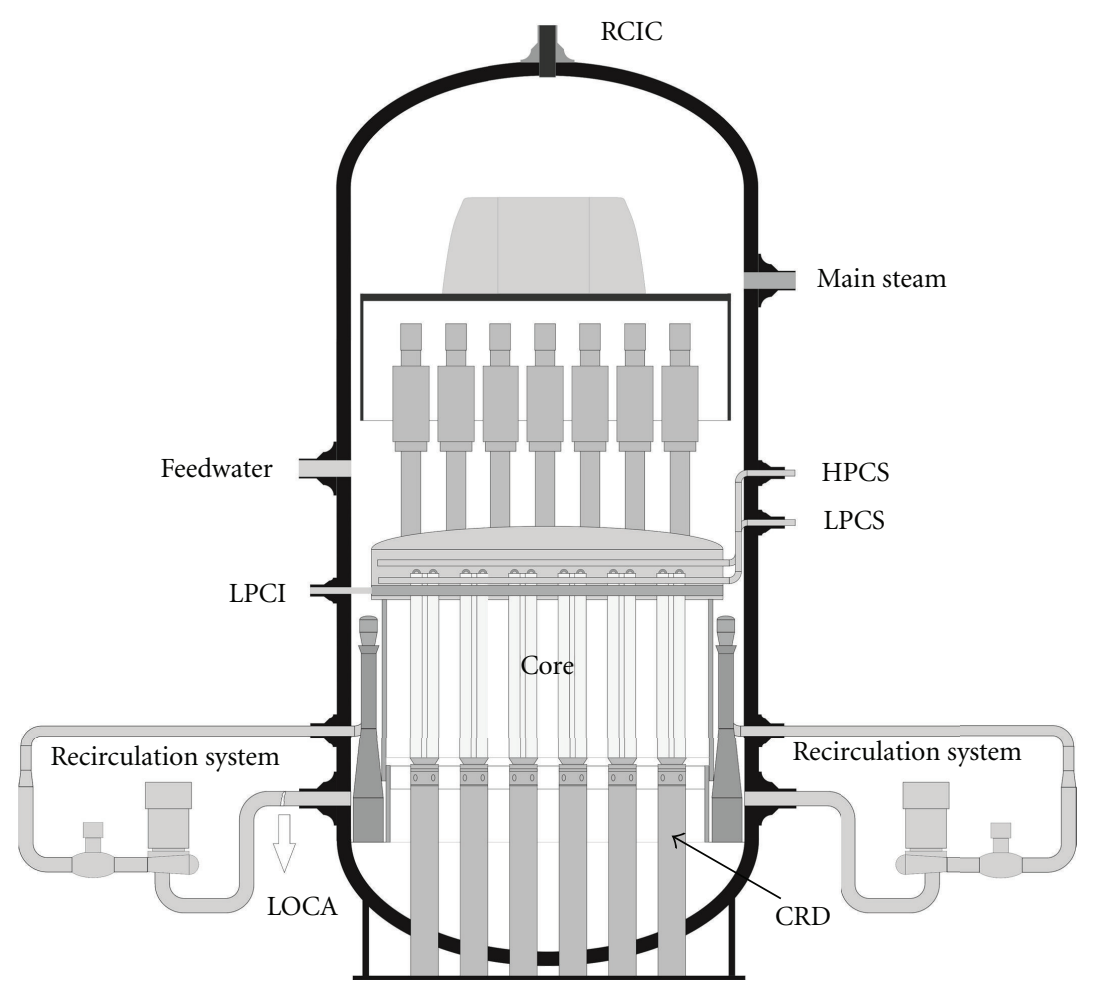

FIGURE 1: Schematic diagram of the boiling water reactor (BWR) [9].

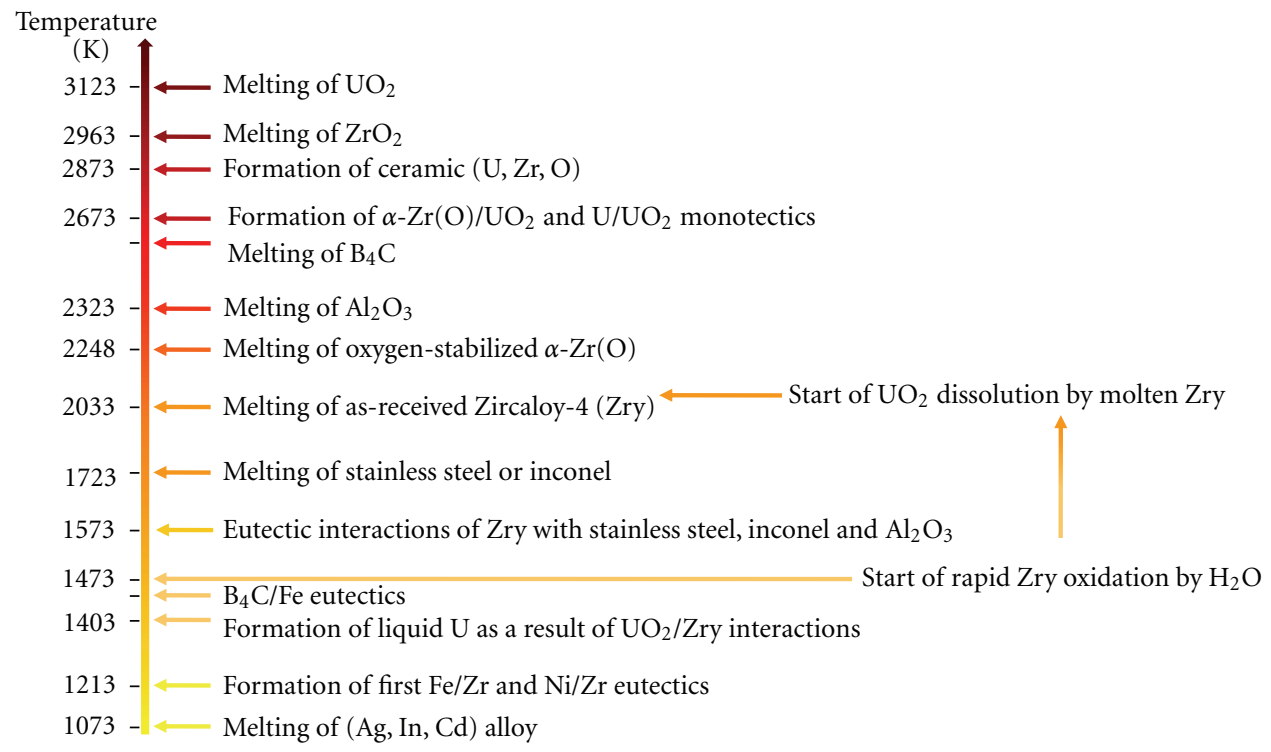

FIgURE 2: Progression of core damage.

systems, the wall of the reactor vessel will fail. If at that time the pressure in the reactor coolant system is low, the corium will flow down the cavity of the container. If the pressure is high, the corium is violently eject and dispersed. The impacts on the containment due to these two scenarios are completely different, but in both cases, the containment can fail early or late or even may remain intact.

3.1. Core Damage Progression. As a result of heat produced by radioactive decay of the active elements, known as the decay energy, the fuel temperature begins to rise, even when the reactor is off after a scram, if the core cooling is inadequate [12].

In the case of severe accidents, where it is anticipated that the safety engineering systems (IS) functions incorrectly, to the extent that the core loses its cooling, the core will be damaged by overheating and release radioactive elements, mainly the primary system reactor.

At temperatures of $1073 \mathrm{~K}$, molten occurs of the alloy Ag-In-Cd of the control rod for pressurized water reactors 
(PWRs, Figure 2), the molten alloy is thermodynamically stable within the fuel element due to pressure vapor of the alloy, especially due to cadmium. For BWR, the molten of the control rods occurs around $1,500 \mathrm{~K}$, and according with CORA 17 experiment, the release of energy and hydrogen production is higher than a PWR as the steam reaction with the remnant $\mathrm{B}_{4} \mathrm{C}$, absorber of the BWR control rods, is more exothermic per gram of material than Zircaloy during the quench phenomenon [13].

The guide tube failure will cause the attack of the alloy Zircaloy of the fuel element. The liquid mixture may fall down by gravity effects and move into the core regions, causing localized damage in the fuel cladding. Eventually is resolidified and may produce blockage in cold areas of the lower region of the core region.

At temperatures around $1173 \mathrm{~K}$, the zirconium of the fuel cladding begins to react chemically with steam, which produces hydrogen and reaction heat.

At temperatures above $1500 \mathrm{~K}$, the reaction becomes very large, accelerating overheating of the fuel, the oxidation of zircaloy $(\mathrm{Zr})$ of the fuel cladding by steam effects, it becomes important. This reaction is exothermic and the temperature increases the rate of oxidation increases, the energy release is large as well as the generation of hydrogen $\left(\mathrm{H}_{2}\right)$.

The hydrogen production rate depends on the temperature of zirconium in the core and the amount of steam available. When the temperature rises about $1500 \mathrm{~K}$, the following reaction can be carried out:

$$
\mathrm{Zr}+2 \mathrm{H}_{2} \mathrm{O} \longrightarrow \mathrm{ZrO}_{2}+2 \mathrm{H}_{2}+586 \mathrm{~kJ} / \mathrm{mol} .
$$

On the other hand, the heating of the fuel elements results in loss of mechanical properties with consequent ballooning that can lead to breakage. The deformation occurs due to the difference in pressure between the inside of the fuel element and reactor pressure. The internal pressure of the fuel element is a function of fuel temperature on the thermodynamic process of heating at constant volume. Regarding the reactor pressure will depend on the type of accident. Large breaks in the primary cooling system have much higher risk of ballooning when the pressure of the system mentioned above is almost atmospheric.

The effects of ballooning in the fuel elements are mainly to (1) reduce the passage section of coolant flow in the core and (2) hinder the cooling of localized areas of the fuel. Both phenomena lead a further increase in temperature and higher deformation. In addition to the deformation by pressure difference, it also can occurs due to thermal expansion. Another possible mechanism is the breaking strain differential expansion between the oxide layer and the inner layer of metal. This latter mechanism may induce breakage of oxidized fuel element even without differential pressure. The break of the fuel rods produces that the reaction between steam and cladding increases twice.

Experiments have shown that the rupture of the fuel does not block the flow of steam but whether it deviates by reducing the natural flow in the core. The fuel temperature increases and most of the hydrogen generated in the accident occur during this early stage.
At intermediate temperatures ( 2033 and $2273 \mathrm{~K}$ ), if the thickness of the oxide layer is sufficiently large, the oxide will retain the $\mathrm{Zr}$ molten metal, preventing the fall down by gravity and staying in touch with the pellets of dioxide uranium $\left(\mathrm{UO}_{2}\right)$, which will remain until the outer layer of oxide loses their resistance due to its dissolution by molten $\mathrm{Zr}$ or due to mechanical failure or because it reaches the melting temperature $(2963 \mathrm{~K})$ of $\mathrm{ZrO}_{2}$.

If the fuel element has ballooned previously, the ability to contact the pellets will be reduced, thereby reducing the ability of $\mathrm{UO}_{2}$ dissolution. In the analysis of severe accidents, the phenomenology is very important because it is capable of producing nuclear fuel liquefaction temperatures (1000 K) below the melting point of the $\mathrm{UO}_{2}(3123 \mathrm{~K})$, where the interaction process is complex.

At temperatures above $2873 \mathrm{~K}$ will occur the melting of ceramic materials $\mathrm{UO}_{2}, \mathrm{ZrO}_{2}$ and mixed oxide $(\mathrm{U}, \mathrm{Zr}) \mathrm{O}_{2}$, and total loss of the geometry of the affected zone.

\section{Severe Accident Scenarios for the LVNPP}

The severe accidents simulations consider the occurrence of the postulated LOCA in the recirculation loop of the reactor (Figure 1), with water coolant injection with HPCS at different times. Also, another scenario considered the postulated LOCA without water coolant injection. For this study, we used as a reference the data presented in Figure 2, which is information that Innovative Systems Software (ISS) has published [11] and that is generally similar the reference [14].

\section{Numerical Model of the LVNPP}

The nuclear steam supply system (NSSS) whose function is to carry the steam from the reactor vessel to the main turbine, and then drive the feed-water flow from the condenser to the vessel, holding constant all parameters in the reactor. The NSSS model representing the LVNPP using SCADAP/ RELAP5 is illustrated in Figure 3. The operating conditions correspond to power uprate (PU) LVNPP, that is, $2027 \mathrm{MWt}$ of the thermal power rate. This model includes the following main elements: (1) feed-water system, (2) reactor vessel and internals, (3) recirculation loops, (4) the reactor core, (5) main steam line, (6) bottom of the reactor vessel. The bottom model of the vessel is a fundamental element for the analysis in accident scenarios, for which it is included as a separate element that interacts with the other models.

\section{Numerical Experiments}

In order to evaluate the effect of time on the core cooling, we considered various cases, starting from a steady-state reactor of the LVNPP at to power uprate conditions (2027 MWt). In particular, we present the results and discussions of three conditions at different times of injection of HPCS, for reference conditions Which were determined without the performance of security systems, subsequently with damage in the core region was injected coolant flow with the HPCS 


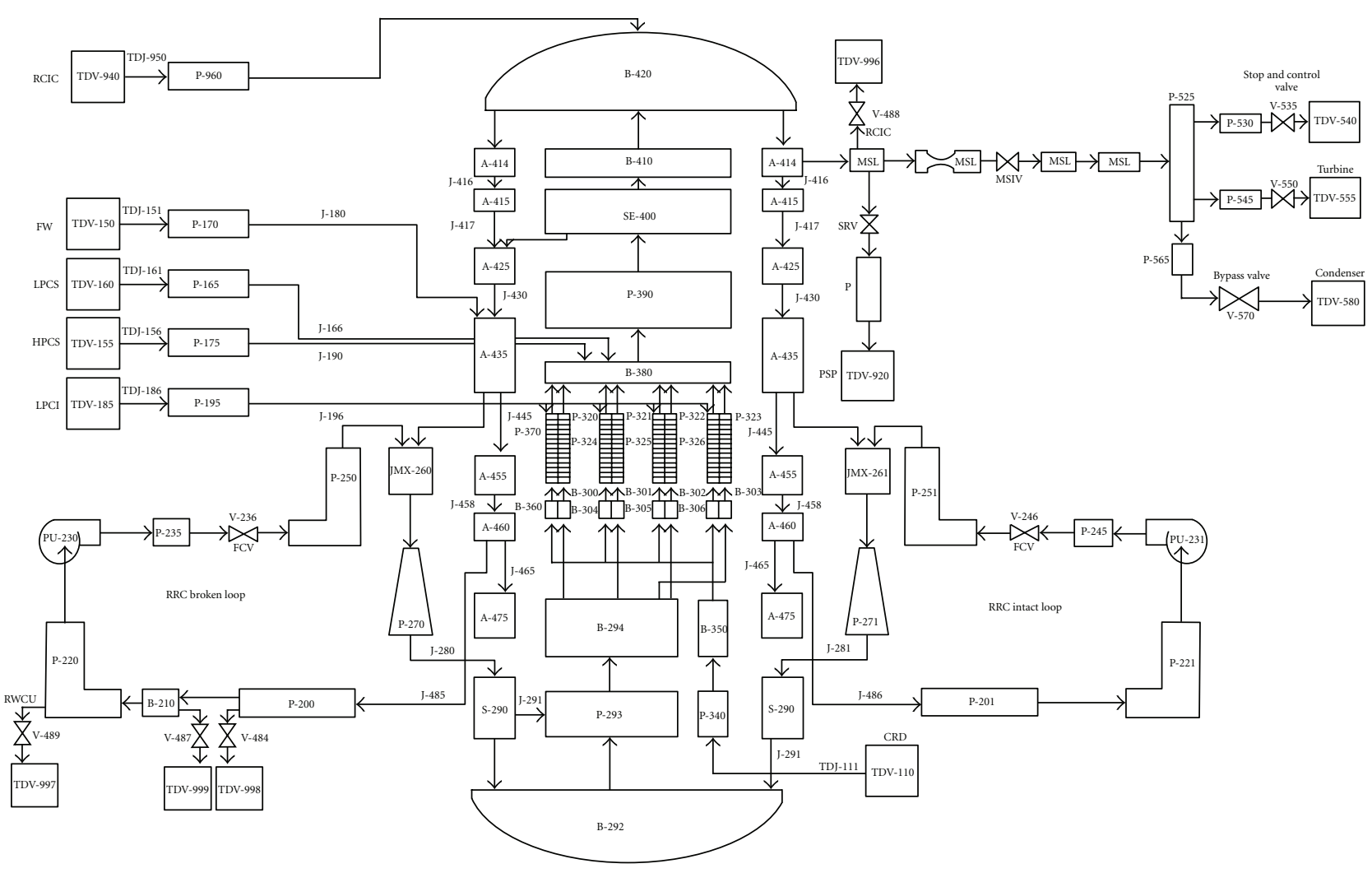

Figure 3: SCADAP/RELAP5 Laguna Verde Nuclear Power Plant model [22].

at 700, 900, $1200 \mathrm{~s}$; therefore, four numerical experiments are analyzed in this work.

For each numerical experiment the following parameters were analyzed:

(i) collapsed level,

(ii) pressure in the dome of the vessel,

(iii) maximum surface temperature in the core region,

(iv) noncondensable fission products released,

(v) soluble fission products released.

(vi) hydrogen generation,

(vii) core damage,

(viii) control rod damage,

(ix) debris bed height in lower plenum.

\section{Simulations and Discussions}

A comprehensive analysis of the nuclear reactor during the transient evolution for the LOCA event with and without cooling is presented in this section.

The studied scenario (base case) is a loss of coolant accident (LOCA) due to rupture of a pipe in a recirculation circuit, imposing no coolant flow injection in the core region. This causes the signal to activate isolation of main steam (MS) and activates the coolant injection systems. Due to this, recirculation pumps trips and reactor scram occure.
Subsequently, we expected decrease of the thermal power, level, pressure in the dome, steam flow, feed-water flow, and mass flow rate in the core, the close of the main steam insolation valves (MISVs) and trips the feed-water turbine pumps. The reactor collapsed level drops dramatically activating the emergency core cooling systems but these do not provide coolant flow, which causes damage in the core region.

The sequence of events is presented in summary form in Table 1, for the case without cooling effects. In this table, it is observed that the hypothetical accident due to LOCA and no available emergency systems to cooling core, where at $324 \mathrm{~s}$ the hydrogen generation starts. Oxidation of the cladding, rods, and other components in the core constructed in zirconium base alloy, by steam, is a critical issue in LWR accident producing severe core damage. During a severe accident in a nuclear reactor, several works are focusing on core degradation by metal core components oxidation by air or steam (e.g., [15-18]), on the other hand, Royl et al. [19] have made a hydrogen risk analysis during severe accident using computational fluid dynamics (CFD) codes, to obtain localized detailed information and supplement the results of lumped parameter codes, which focus on global or average effect.

In this table, the maximum surface temperature in the core at different times match the event which is related with the progression of the core damage as is illustrated in the schematic diagram of the Figure 2.

The numerical results of nuclear reactor during the transient evolution for the LOCA event with and without cooling are presented in Figures 4-10. 
TABLE 1: Main sequence of events in a LOCA without cooling effects.

\begin{tabular}{|c|c|}
\hline $\begin{array}{l}\text { Time } \\
\text { (seconds) }\end{array}$ & Event \\
\hline 0.0 & $\begin{array}{l}\text { The reactor operates to power uprate conditions } \\
(2027 \mathrm{MWt}) \text {. }\end{array}$ \\
\hline 30.0 & $\begin{array}{l}\text { Loss of external power, loss of coolant in a } \\
\text { recirculation loop, closing of the turbine control } \\
\text { valves, and trip of the reactor and recirculation } \\
\text { pumps. }\end{array}$ \\
\hline 34.3 & $\begin{array}{l}\text { Low level in the reactor vessel (L2), before high } \\
\text { pressure occurs in the drywell. The emergency core } \\
\text { cooling systems (HPCS* and RCIC*) are active } \\
\text { without injecting. Starts closing insolation valves } \\
\left(\text { MSIV }^{*}\right) \text {. }\end{array}$ \\
\hline 37.4 & Low-low level (L1) is reached. \\
\hline 40.0 & Level in the BAF*. \\
\hline 200.0 & Level below the core support plate. \\
\hline 324.0 & Hydrogen generation starts. \\
\hline 370.0 & $\begin{array}{l}\text { Maximum temperature at the core surface of } \\
1073 \mathrm{~K} .\end{array}$ \\
\hline 458.0 & $\begin{array}{l}\text { Core damage stage starts with release of fission } \\
\text { products. } \\
\text { Maximum Temperature at the core surface of } \\
1185 \mathrm{~K} .\end{array}$ \\
\hline 936.0 & $\begin{array}{l}\text { Control rod damage starts } \\
\text { Maximum temperature at control rod of } 2136 \mathrm{~K} \text {. }\end{array}$ \\
\hline 1800.0 & Core damage de $19 \%$. \\
\hline 3600.0 & Core damage of $78 \%$. \\
\hline
\end{tabular}

${ }^{*}$ HPCS: high pressure core spray system; RCIC: reactor core isolation cooling; MISV: main steam insolation valves; BAF: bottom of active fuel.

The core melt accident progression can be divided into two stages.

(1) An early phase up to the partial melting of core material, where involves core uncover, heat up, and partial melting in the reactor core region.

(2) A late phase results in the significant melting of the core material with relocation, and redistribution in the lower plenum. The governing phenomena involves porous debris bed, molten pool, and formation cavity, where the process heat, momentum, and mass are complex due to very high temperatures, multicomponent and multiphase materials, melting and freezing process, and geometrical configurations.

In general terms, if not cooled in the core region, the molten core materials (known as corium that is a conglomerated mixture of various core materials; mainly but not exclusively as oxide component- $\mathrm{UO}_{2}$, and $\mathrm{ZrO}_{2-}$, metallic components- $\mathrm{U}, \mathrm{Zr}, \mathrm{Fe}$, and stainless steel), accumulated on the core support plate, would be eventually relocated into de lower plenum region and the thermal attack on the lower plenum could occur. In the presence of water in the lower plenum, some portions of the relocating molten core material could be fragmented into small solid particles in the lower head, and the remain material will maintain its original

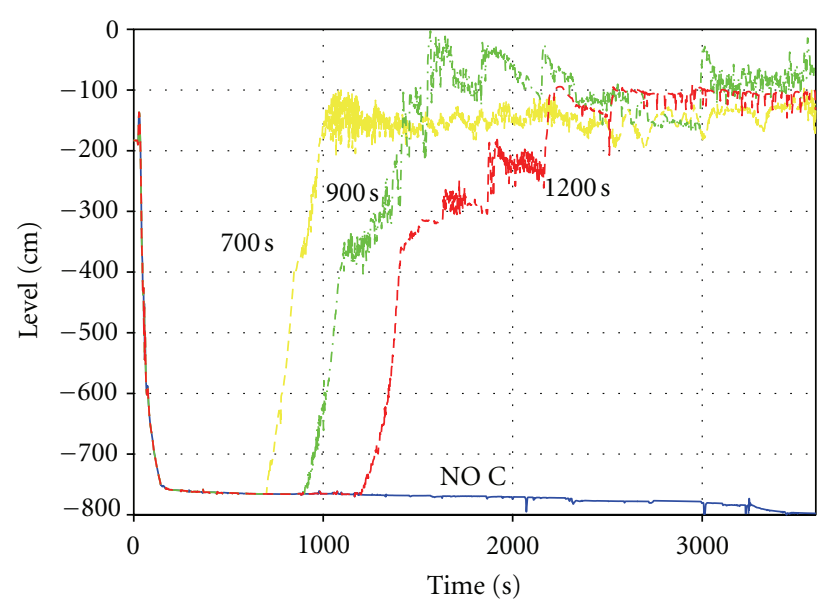

FIgURE 4: Level respect to top of active fuel (TAF) or fuel zone. HPCS injection to $700 \mathrm{~s}, 900 \mathrm{~s}$, and $1200 \mathrm{~s}$; NO C indicates without HPCS injection.

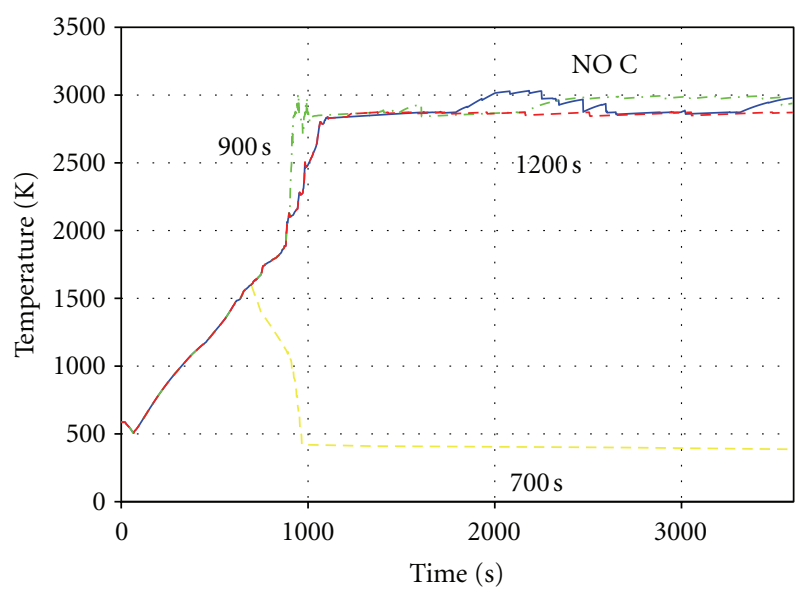

FIGURE 5: Maximum surface temperature in the core. HPCS injection to $700 \mathrm{~s}, 900 \mathrm{~s}$, and $1200 \mathrm{~s}$; NO C indicates without HPCS injection.

liquid phase [8]. The main mechanism of fragmentation (debris jet) is a hydrodynamics process, where rapid heat transfer from the debris jet to the lower plenum water accompanies the hydrodynamic fragmentation process and debris oxidation, results in steam and hydrogen production and an abrupt increase of the pressure. The heat removal from the lower head debris bed is determined by amount of the heat generated in the corium accumulated in the lower plenum, heat transfer inside the core material, heat transfer from the corium to the reactor vessel, and heat transfer to outer vessel.

7.1. Level Behavior. The transient behavior comparison of the level in the vessel respect to TAF (Top of Active Fuel) with and without cooling is shown in Figure 4. This figure shows that core is discovered for all cases analyzed in this work. The core discovers that time is crucial for the progression of the core damage, due to the temperature of the core region increase, even be lost cooling capacity. In all cases 


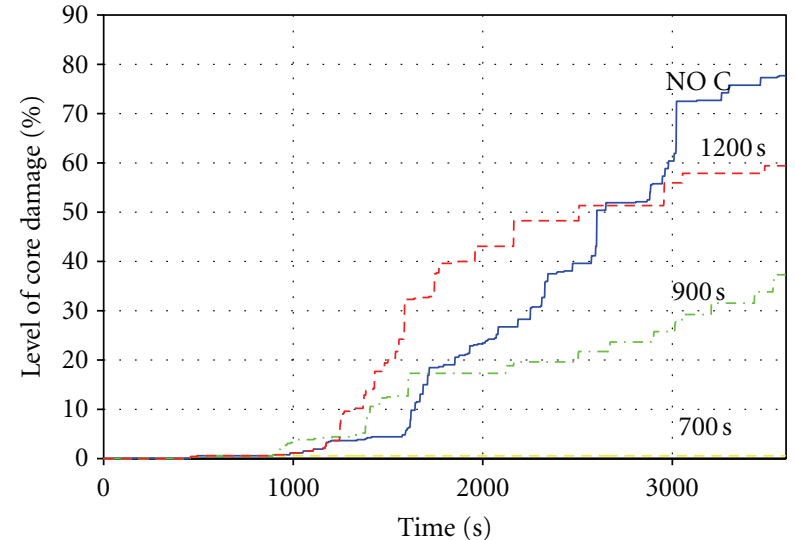

FIGURE 6: Level of core damage. HPCS injection to $700 \mathrm{~s}, 900 \mathrm{~s}$, and $1200 \mathrm{~s}$; NO C indicates without HPCS injection.

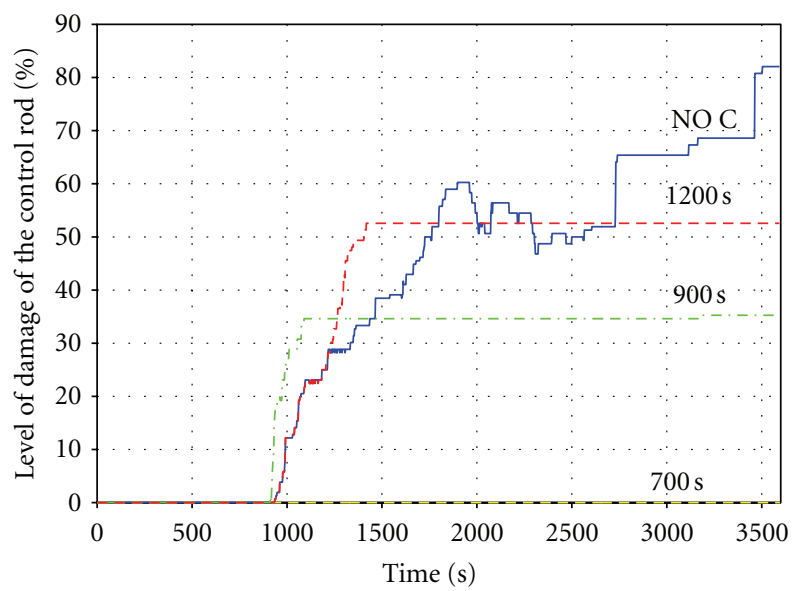

Figure 7: Level of damage of the control rod. HPCS injection to 700 s, 900 s, and 1200 s; NO C indicates without HPCS injection.

in which the coolant injected, recovering refrigerant level in the reactor vessel is according to the time of action of HPCS (Figure 4).

According with these results when the HPCS started, the water level in the vessel is partially recovered to ensure the reactor core cooling. Approximately in $-400 \mathrm{~cm}$, the increased level presents a change in trend accompanied (or mounted) by oscillations apparently of high frequencies, and these are very strong when the core is practically covered $(-150 \mathrm{~cm}$ of the level) especially for the case of $700 \mathrm{~s}$ of HPCS injection, which is presented between 1000 to $1500 \mathrm{~s}$ of elapsed time in the simulation. These effects are produced due to convective heat transfer process between core region and the cooling where the rapid change of liquid phase to gas phase occurs, which causes variations of the pressure in the reactor vessel, these being the main phenomena. Regarding the $900 \mathrm{~s}$ of HPCS injection, it can be seen that these effects occur immediately after the coolant interacts with the core region which occurs at $-400 \mathrm{~cm}$ of water level, while that for the case to $700 \mathrm{~s}$ occurs at $-150 \mathrm{~cm}$ of water level. These differences between two cases (700 and 900 s HPCS injection)

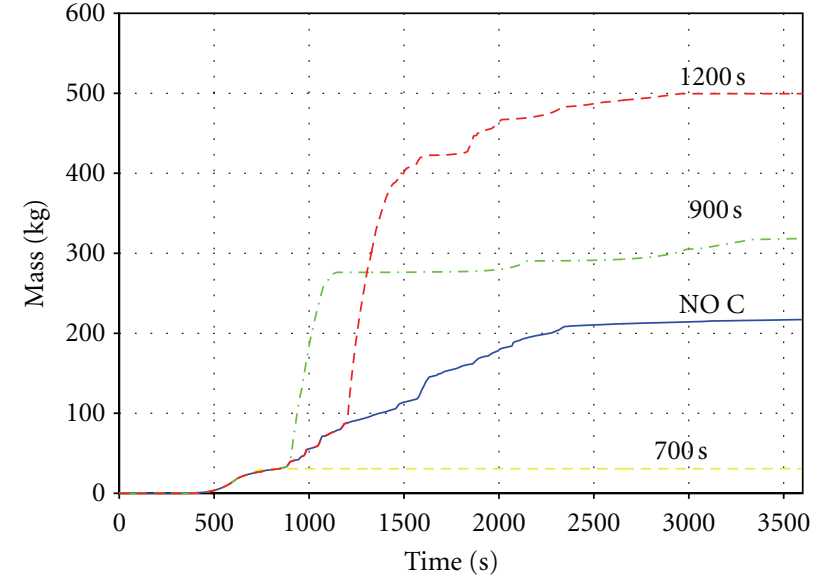

FIgure 8: Core total hydrogen generation $(\mathrm{kg})$. HPCS injection to 700 s, 900 s, and 1200 s; NO C indicates without HPCS injection.

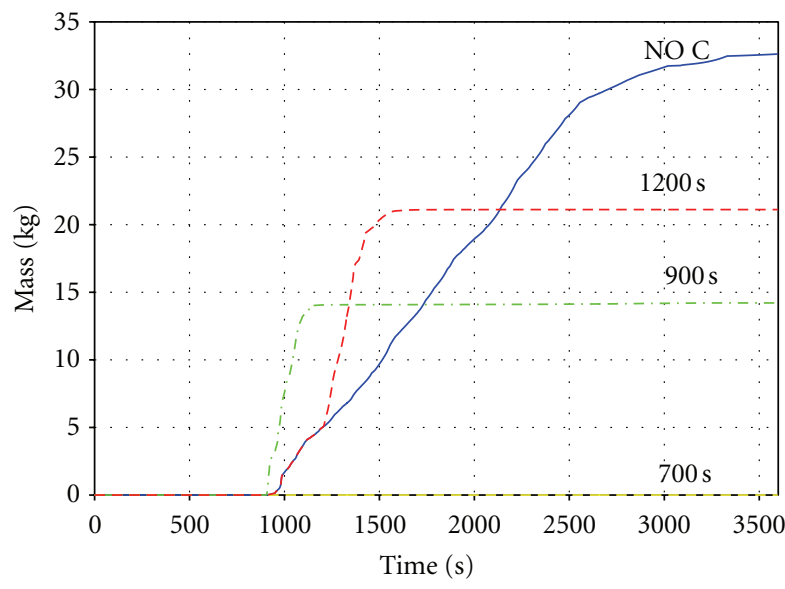

FIGURE 9: Noncondensable fission product released. HPCS injection to $700 \mathrm{~s}, 900 \mathrm{~s}$, and $1200 \mathrm{~s}$; NO C indicates without HPCS injection.

are the energy accumulated in the core region being higher for $900 \mathrm{~s}$. Then, removing energy (900 s) with the same water flow of the HPCS is more complex respect to $700 \mathrm{~s}$, which can be inferred due to the greater instabilities (respect to $700 \mathrm{~s}$ ) along the simulation time (see $900 \mathrm{~s}$ in the Figure 4).

In the case of the $1200 \mathrm{~s}$ of HPCS injection, the water level in the reactor vessel is recovered but with significant lower stability, that is, apparently the steam by convective effects and heat transfer mechanism by radiation remove heat generated and accumulated in the core region at this time (1200 s) before the injection of HPCS; also can be observed some agglutinated oscillations of the level in approximately $-300 \mathrm{~cm}$ and $-200 \mathrm{~cm}$ characteristics the thermodynamics effects due to phase changes or due to pressure changes. For the case without HPCS injection, the progression of the core damage is expected and the consequences were widely discussed previously.

7.2. Maximum Surface Temperature in the Core. The behavior of the maximum surface temperature in the core is 


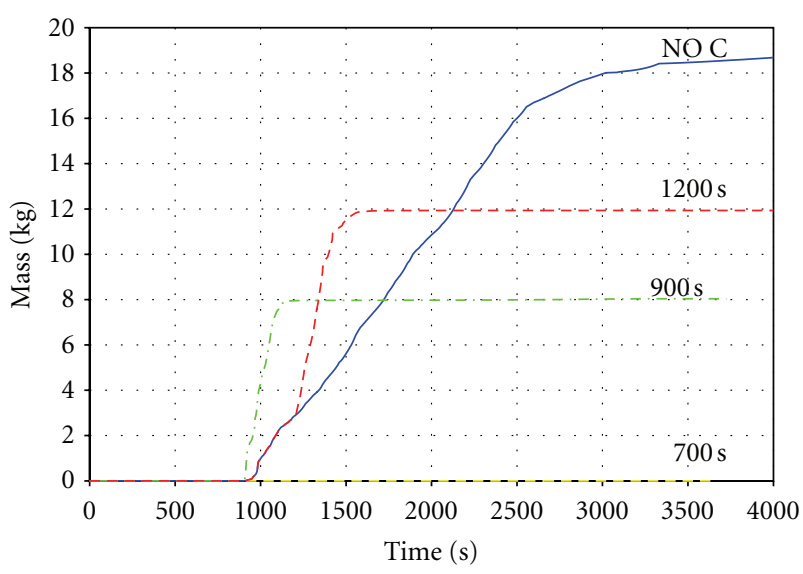

Figure 10: Soluble fission products released. HPCS injection to $700 \mathrm{~s}, 900 \mathrm{~s}$, and $1200 \mathrm{~s}$; NO C indicates without HPCS injection.

presented in Figure 5. For the case of 700 s of HPCS injection, the temperature increases linearly to a temperature of $1600 \mathrm{~K}$ at $700 \mathrm{~s}$ the elapsed time, under this conditions some fuel elements fail. When acts the HPCS at $700 \mathrm{~s}$; the temperature decreases to $401 \mathrm{~K}$ at $900 \mathrm{~s}$ of elapsed time, due to presence of coolant removing the heat in the core region primarily by convective mechanism.

For the rest of the numerical experiments, that is, with cooling (HPCS injection to $900 \mathrm{~s}, 1200 \mathrm{~s}$ ), and without cooling, it does not cool the core region, as can be observed in Figure 5. However, there are some peculiarities that it should be noted.

(1) At $900 \mathrm{~s}$ of HPCS injection, the temperature is approximately of $2126 \mathrm{~K}$ that represents conditions of significant core damage, in this case the presence of the coolant flow apparently increases the core damage due to presence the two temperature peaks of approximately of $3000 \mathrm{~K}$. The interpretation physical of this peaks is that the chemicals reactions with materials of the core region (control rod, uranium oxide, $\mathrm{Zr}$, etc.) in average are exothermic, this occurs in time lapse of $900 \mathrm{~s}$ to $1000 \mathrm{~s}$ the elapsed time, after this time, the temperature decreases to approximately to $2750 \mathrm{~K}$, which is maintained until $2200 \mathrm{~s}$ of elapsed time, and after of this time, the temperature increases again to $3000 \mathrm{~K}$, indicating the presence of complex phenomena such as loss geometry in the core region, therefore, some loss of cooling capacity due to coolant flow blockage.

(2) For the case of $1200 \mathrm{~s}$ of the HPCS injection and without cooling (NO C in Figure 5), the temperature behavior follows the same trends until $1800 \mathrm{~s}$ the elapse time, that is, the behavior is practically the same with and without cooling. It is important to note for cooling case at $1200 \mathrm{~s}$, that the temperature is increased until of $2750 \mathrm{~K}$ and remains around this value from the $1150 \mathrm{~s}$ to complete simulation, that is, the presence of coolant flow is not responsible that for the temperature does not increase further, due to that the inflexion point occurs $150 \mathrm{~s}$ before injection of HPCS.

(3) For the case without cooling of the core region as was previously mentioned, the temperature behavior follows the same trends of the HPCS injection until $1800 \mathrm{~s}$, in this time, a temperature increase can be observed slightly more than $3000 \mathrm{~K}$, and at $2600 \mathrm{~s}$ of the elapse time, the temperature decreases to $2750 \mathrm{~K}$, then afterward, therecan be observed some increases.

The preliminary conclusions according with the behavior of maximum surface temperature in the core, with and without cooling in the core region are as follows: (1) The injection of the HPCS at $700 \mathrm{~s}$, cooling is achieved properly of the core region and the consequence of core damage can be stopped. (2) The injection of the HPCS at $900 \mathrm{~s}$ can be not recommendable due to exothermal process that cause large increase of the temperature (temperatures peaks) in the core region. (3) The injection of the HPCS at $1200 \mathrm{~s}$ has not significant effect and the behavior is similar to without cooling, apparently due to the loss of cooling capacity due to loss of geometry of the core region.

The energy accumulated and generated by different process such as chemical reactions is a indicative that the time the injection is crucial as after the core region, it is not possible to cool (with HPCS), at least at short times, the order of the hours. Also as is showed by results, the injection at $900 \mathrm{~s}$ generates higher thermal shock, which may make it harder to mitigate core damage.

Figure 5 is obtained using the variable BGMCT of RELAP/SCDAPSIM that represent the maximum temperature in the surface of the core, this case is observed that the maximum temperature in the surface of one axial node remains high even after the injection of the HPCS, this is because of the loss of configuration of the core, the hottest axial node is not cooled.

7.3. Level of the Core Damage. The behavior of the level of the core damage is presented in Figure 6. This result provides sufficient information to establish the effect of time of injection of cooling water to the core region. In this figure, it can be see that the simulation start with little core damage before of $500 \mathrm{~s}$ for four analyzed cases, that is, with injection (HPCS to 700, 900, and $1200 \mathrm{~s}$ ) and without cooling the core region. The core damage that is represented in the $Y$ axis (Figure 7) refers to $0 \%$ when all the axial nodes of the core fuel bundles are intact, and 100\% refers when the whole axial nodes of the fuel bundles are in an intermediate stage as ballooning, rubble, and cohesive debris or molten. This core damage is a consequence of the deficiency or lack of cooling the reactor for a prolonged period of time; in this case, the core damage is presented at approximately $750 \mathrm{~s}$. According to Figure 6 , the level of core damage is about $1 \%$ for the case where the HPCS injection acts at $700 \mathrm{~s}$.

Now, in the following analysis, we take as a reference the behavior without HPCS injection (NO C) to emphasize the importance of time of injection of cooling water in the core region. In Figure 6, it can be seen that without HPCS injection the core damage remains unchanged at a minimum 
value $(1 \%)$ until about $1000 \mathrm{~s}$, and after this time the core damage increases. When the injection is at $900 \mathrm{~s}$, the level of the core damage is greater than without cooling until $1750 \mathrm{~s}$ where the core damage rate increases slightly. For the case HPCS injection at 1200, this behavior is observed, that is, the level the core damage with and without cooling is practically the same until the $1250 \mathrm{~s}$, after the presence of the cooling water accelerates the core damage whose increase is greater than without cooling case, after $1700 \mathrm{~s}$, this behavior is reversed as can be observed in Figure 6.

In summary form, these results indicate that possible negative effect of cooling can be observed in cases of HPCS injecting at 900 to $1200 \mathrm{~s}$, where a sudden increase (at early times of the injection) to the core damage is fully associated with the entry of coolant into the reactor, being greater the core damage than without coolant injection. However, in Figure 6, it can be observed that the rates of core damage decrease due to the phenomena associated with the heat removal.

7.4. Average Level of Control Rod Damage. The behavior of the level of the core damage is presented in Figure 7. According to these results in general terms, the negative effect of cooling can be observed in cases of HPCS injected at 900 to $1200 \mathrm{~s}$, where a sudden increase to the control rod damage is fully associated with the entry of coolant flow into the core region, being greater than without injection for time elapse of $1400 \mathrm{~s}$ and $1800 \mathrm{~s}$, respectively. We must notice that the level of damage in the control rods is a function of the cooling rate; therefore, the damage is greater when the cooling starts late or is missing. The control rods damage that is represented in the $Y$ axis (Figure 7 ) refers to $0 \%$ when all the axial nodes of the control rods are intact, and $100 \%$ refers when the whole axial nodes of the control rods are not intact. In Figure 6, it is observed that the level of damage of the control rod decreased between $2250 \mathrm{~s}$ and $2600 \mathrm{~s}$ is an abnormal behavior and is attributable to a mistake in the version 3.2 of RELAP/SCDAPSIM.

7.5. Hydrogen Generation. The behavior of the hydrogen generation in the core region is presented in Figure 8. The hydrogen generation is coming mainly from the Zircaloy cladding oxidation and partly from the boron carbide oxidation of the control rod. In this figure, it can be observed that the level more low of hydrogen generation is when the HPCS injection acts at $700 \mathrm{~s}$, and, therefore, the heat of reaction is less about the other cases studied. Now, when the HPCS injection acts at $900 \mathrm{~s}$ and $1200 \mathrm{~s}$, the masses of the hydrogen generation are practically 11 (which is generated in $150 \mathrm{~s}$ ) and 17 (is generated in $250 \mathrm{~s}$ ) times greater than the case of the HPCS injection at $700 \mathrm{~s}$ ( $31 \mathrm{~kg}$ of hydrogen generated), respectively. Finally, in $3500 \mathrm{~s}$ of the elapsed time, the mass generated for the case of $900 \mathrm{~s}$ (HPCS injection) is $320 \mathrm{~kg}$ and for the case of $1200 \mathrm{~s}$ (HPCS injection) is $500 \mathrm{~kg}$. In both cases, the rate of the heat due to oxidation reaction is very high with respect to the case of $700 \mathrm{~s}$ of HPCS injection. For the case without cooling with the HPCS, the mass of the generation hydrogen was $220 \mathrm{~kg}$, being 7 times higher than the case of $700 \mathrm{~s}$ (HPCS injection).

From the point of view of hydrogen generation, it can be observed of the simulations results in Figure 8, that the following hold:

(1) Hydrogen production is maintained at a low level if the coolant flow is appropriate at the right time (in this work correspond to $700 \mathrm{~s}$ of the HPCS injection).

(2) If the coolant flow is not appropriate at the right time (cases 900 and $1200 \mathrm{~s}$ of HPCS injection), the hydrogen generation increases to more than one order of magnitude, due to coolant flow entering the core region, including the lower the hydrogen generation is smaller than without cooling as is shows in Figure 8.

(3) The consequences are the following: for the cases of the $900 \mathrm{~s}$ and $1200 \mathrm{~s}$, the HPCS injection produces high rates of hydrogen generation due to oxidation and therefore high rates of heat of reaction because it is an exothermic reaction (clearly predominates in this numerical experiment this mechanism), which produces high temperatures at the core surface near $3000 \mathrm{~K}$ as is observed in Figure 5. Then, the reaction heat is crucial in the cooling of the core region, and the HPCS injection under these conditions is insufficient to cool the core region.

(4) The core and control rod damage (Figures 6 and 7, resp.) has two components that predominate; the first is the time without cooling flow, and reaction heat due to hydrogen generation.

7.6. Fission Products Released from Core Region. The prediction of the behavior of the released fission products from the core are presented in Figure 9 for noncondensable fission products and in Figure 10 for soluble fission products. The released fission products are a function of the level of the core and control rod damage (as was discussed previously in Figures 6 and 7), which is affected by the injection time of the HPCS. According to the progression of the core damage, the mass of fission products (noncondensable and soluble) is higher for the case without cooling (NO C in Figures 9 and 10), which presents higher level of core and control rod damage, with respect to the others cases, that is, $900 \mathrm{~s}$ and $1200 \mathrm{~s}$ (of HPCS injection).

For the case of $700 \mathrm{~s}$ of the HPCS injection, apparently no fission products are released. However, the core damage for this case is less than $1 \%$ (Figure 5) and the control rod damage is null (Figure 7). Obviously, one should expect the minimum amount of fission products released if there is failure the reactor core as shown if Figure 7 (see behavior at $700 \mathrm{~s}$ ).

It is important to note that the release of the fission products contributes to the energy generated and accumulated in the core region; therefore, this fission heat (to call it in some way) the decay heat, reaction heat due to generation of the hydrogen, in other phenomena as melting process causes that the temperature at core region is too high $(3000 \mathrm{~K})$ as can be observed in Figure 5 for the case of the 900 s and 1200 s (of 
TABLE 2: Severe accident (LOCA) with and without cooling.

\begin{tabular}{|c|c|c|c|c|}
\hline Parameter & Without cooling & $\begin{array}{l}\text { HPCS injection at } \\
700 \mathrm{~s}\end{array}$ & $\begin{array}{l}\text { HPCS injection at } \\
900 \mathrm{~s}\end{array}$ & $\begin{array}{l}\text { HPCS injection at } \\
1200 \mathrm{~s}\end{array}$ \\
\hline Level & $\begin{array}{l}\text { Below the core } \\
\text { support plate }\end{array}$ & $\begin{array}{l}\text { Below the core } \\
\text { support plate. After is } \\
\text { recovers }\end{array}$ & $\begin{array}{l}\text { Below the core } \\
\text { support plate. After is } \\
\text { recovers }\end{array}$ & $\begin{array}{l}\text { Below the core } \\
\text { support plate. After is } \\
\text { recovers }\end{array}$ \\
\hline Pressure & $\begin{array}{c}\text { Low by } \\
\text { decompression }\end{array}$ & $\begin{array}{c}\text { Low by } \\
\text { decompression }\end{array}$ & $\begin{array}{c}\text { Low by } \\
\text { decompression }\end{array}$ & $\begin{array}{c}\text { Low by } \\
\text { decompression }\end{array}$ \\
\hline $\begin{array}{l}\text { Maximum surface } \\
\text { temperature in the core }(\mathrm{K})\end{array}$ & 3028.00 & $\begin{array}{c}1640.00 \text { (proper } \\
\text { cooling with HPCS) }\end{array}$ & $\begin{array}{c}2960.00 \text { (cooling is } \\
\text { not insured with } \\
\text { HPCS) }\end{array}$ & $\begin{array}{l}3000.00 \text { (cooling is } \\
\text { not insured with } \\
\text { HPCS) }\end{array}$ \\
\hline $\begin{array}{l}\text { Non-condensable fission } \\
\text { product }(\mathrm{kg})\end{array}$ & 33.00 & 0.00 & 19.00 & 21.00 \\
\hline Soluble fission product $(\mathrm{kg})$ & 18.70 & 0.00 & 8.00 & 11.90 \\
\hline Hydrogen generation (kg) & 218.70 & 30.70 & 319.50 & 499.50 \\
\hline Debris bed height $(\mathrm{m})$ & 0.36 & 0.00 & 0.23 & 0.21 \\
\hline Core damage (\%) & 77.70 & 0.60 & 37.30 & 59.40 \\
\hline Control rod damage (\%) & 82.10 & 0.00 & 35.30 & 52.60 \\
\hline
\end{tabular}

HPCS injection). At this point in the analysis and discussion of the results, we see that the injection of water for the cases of 900 and 1200, generating greater amounts of hydrogen (Figure 8), but smaller amounts of fission products released, with respect to the case without cooling (Figures 9 and 10). Figure 9 refers to noncondensable fission product released (krypton, xenon and Iodine), and Figure 10 is the soluble fission products released (Cesium Iodine (CsI) and Cesium hydroxide $(\mathrm{CsOH}))$ during the LOCA $[20,21]$.

The comparisons of the four cases studied in this work are summarized in Table 2. In this table, are presented other variables such as control rod damage, hydrogen generation, and debris bed height, which are included in this analysis. But before addressing these variables, it can be observed in this table that the exposition time without cooling is determined for the progression of core damage, for $900 \mathrm{~s}$ and $1200 \mathrm{~s}$ the cooling cannot assured with HPCS injection, at least in $4000 \mathrm{~s}$ of the simulation. The maximum surface temperature in the core indicates that the melting of $\mathrm{ZrO}_{2}$ and near the melting $\mathrm{UO}_{2}$ for the case without cooling, $900 \mathrm{~s}$ and $1200 \mathrm{~s}$ of HPCS injection. The fission products released for the case without cooling are greater than the other cases but not the hydrogen generation being higher for the cases of $900 \mathrm{~s}$ and $1200 \mathrm{~s}$ of HPCS injection (under this condition, the water accelerated the hydrogen generation, when the temperature of the core region is of the order of $1470 \mathrm{~K}$ ). The core and control rod damage is proportional to the injection time of the HPCS, being maximum for the case without cooling and minimum for $700 \mathrm{~s}$ of HPCS injection.

Now, respect to the debris bed height also can be observed that is proportional to core and control rod damage, being maximum for the case without cooling and null for $700 \mathrm{~s}$ of HPCS injection. The core region molten core materials accumulated on the core support plate would be eventually relocated into de lower plenum region and the thermal attack on the lower head vessel could occur. From phenomenological point of the view, the physical and chemical processes of the core debris are very complex, due to configuration, temperature, and composition. The heat removal from the debris bed in the lower plenum is determined by amount of the heat generated in the molten core materials, heat transfer inside the core material, and heat transfer from the core material to the reactor vessel. In this work, the thermal attack on the lower plenum is not presented, which requires a broad and specific study.

\section{Conclusions}

The severe accident simulation in the BWR of the Laguna Verde Nuclear Power Plant (LVNPP) to 105\% of rated power was analyzed in this work using RELAP/SCDAPSIM code. The severe accidents start with a loss-of-coolant accident (LOCA) in loop of the recirculation of the reactor with and without water cooling injection. The variables analyzed were level, pressure, maximum surface temperature in the core region, maximum temperature of the control rod, fission products released (noncondensable and soluble), hydrogen generation, core and control rod damage, and debris bed height in lower plenum. The numerical experiments consider a little damage in the core with three different times of HPCS injection at $700 \mathrm{~s}, 900 \mathrm{~s}$, and $1200 \mathrm{~s}$. The following results were obtained.

(i) In the case of the $1200 \mathrm{~s}$ of HPCS injection, the level is recovered but with significant lower stability (Figure 4), indicative of the low activity of heat transfer processes, losing the cooling capacity for severe core damage.

(ii) For the case of HPCS injection at $900 \mathrm{~s}$, two temperature peaks in the surface of the core of approximately of $3000 \mathrm{~K}$ were observed when the water cooling was injected (Figure 5). 
(iii) For the case of $1200 \mathrm{~s}$ of the HPCS injection and without cooling, the behavior of the surface temperature in the core is practically until $1800 \mathrm{~s}$ (Figure 5).

(iv) The energy accumulated and generated by different process such as reactions chemical is an indicative that the time the injection is crucial due to that after the core region is not possible to cool, at least a short time the order of the hours (Figure 5).

(v) The negative effect of cooling can be observed in cases of HPCS injecting at $900 \mathrm{~s}$ and $1200 \mathrm{~s}$, where a sudden increase to the core damage is fully associated with the entry of coolant into the core region, being greater than the core damage than without injection (Figure 6).

(vi) The hydrogen generation is higher with coolant injection for the cases of $900 \mathrm{~s}$ and $1200 \mathrm{~s}$ (of HPCS injection) that without coolant injection (Figure 8).

(vii) The fission products released for the case without coolant injection are greater than with coolant injection (Figures 9 and 10).

These results are crucial and can be applied to establishing strategies for LVNPP and development of severe accident guide.

\section{References}

[1] NRC, "Nuclear Regulatory Commission: 10 CRF 100 "Reactor Site Criteria" and 10 CFR 50 Appendix A, Criterion 19 "Control Room"'” 1999.

[2] CFE, Comisión Federal de Electricidad (CFE): Final Safety Analysis Report (FSAR), México, 1979.

[3] Innovative Systems Software, LLC (ISS), "Software, System thermal hydraulics", 2012, http://www.relap.com/sdtp/software.php/.

[4] C. M. Allison and J. K. Hohorst, "Role of RELAP/SCDAPSIM in nuclear safety," Science and Technology of Nuclear Installations, vol. 2010, Article ID 425658, 2010.

[5] RELAP5/MOD3.3 Code Manual Volume I: Code Structure, System Models, and Solution Methods, Nuclear Safety Analysis Division, NUREG/CR-5535/Rev 1-Vol I.

[6] R. Gaunt, R. Cole, C. Erickson et al., "MELCOR Computer code manuals," NUREG/CR-6119, Rev. 1, National Laboratory, USA, 1998.

[7] MAAP4, "MAAP4: Modular accident analysis program for LWR plants, code manual vols. 1-4," Fauske \& Associates Inc., Burr Ridge, Ill, USA, 1994.

[8] K. I. Ahn and D. H. Kim, "A state-of-the-art review of the reactor lower head models employed in three representative U.S. severe accident codes," Progress in Nuclear Energy, vol. 42, no. 3, pp. 361-382, 2003.

[9] BWR/6, BWR/6 General Description of a Boiling Water Reactor, Nuclear Energy Division, General Electric Company, 1975.

[10] Guía de Seguridad No. 1.10, Consejo de Seguridad Nuclear, Madrid, España, 1995.

[11] C. Allison, "Phenomenology of Severe Accident," IAEA sponsored training workshops on Analysis of Severe Accident.

[12] B. De Boeck and D. Gryffroy, "Introduction to severe accidents especially the containment behaviour," AVN-97/013, AIB VINÇOTTE, NUCLEAR, 1997.
[13] S. Hagen, P. Hofmann, V. Noack, L. Sepold, G. Schanz, and G. Schumacher, Comparison of the Quench Experiments CORA12, CORA-13, CORA-17, Forschungszentrum Karlsruhe, 1996.

[14] NUREG/CR-6042, Rev. 2, Perspectives on Reactor Safety, U. S. Nuclear Regulatory Commission, Washington, DC, USA, 2002.

[15] G. Schanz, B. Adroguer, and A. Volchek, "Advanced treatment of zircaloy cladding high-temperature oxidation in severe accident code calculations Part I. Experimental database and basic modeling," Nuclear Engineering and Design, vol. 232, no. 1, pp. 75-84, 2004.

[16] C. Duriez, M. Steinbrück, D. Ohai, T. Meleg, J. Birchley, and T. Haste, "Separate-effect tests on zirconium cladding degradation in air ingress situations," Nuclear Engineering and Design, vol. 239, no. 2, pp. 244-253, 2009.

[17] M. Steinbrück, "Prototypical experiments relating to air oxidation of Zircaloy-4 at high temperatures," Journal of Nuclear Materials, vol. 392, no. 3, pp. 531-544, 2009.

[18] E. Beuzet, J. S. Lamy, A. Bretault, and E. Simoni, "Modelling of Zry-4 cladding oxidation by air, under severe accident conditions using the MAAP4 code," Nuclear Engineering and Design, vol. 241, no. 4, pp. 1217-1224, 2011.

[19] P. Royl, H. Rochholz, W. Breitung, J. R. Travis, and G. Necker, "Analysis of steam and hydrogen distributions with PAR mitigation in NPP containments," Nuclear Engineering and Design, vol. 202, no. 2-3, pp. 231-248, 2000.

[20] SCDAP/RELAP5/MOD3.2 Code Manual, Volume II: Damage Progression Model Theory, NUREG/CR-6150, INEL-96/0422, Revision 1, October 1997.

[21] SCDAP/RELAP5/MOD3.2 Code Manual Volume IIII: User's Guide and Input Manual, NUREG/CR-6150, INEL-96/0422, Revision 1, November 1997.

[22] G. Espinosa-Paredes and A. Nuñez-Carrera, "SBWR model for steady state and transient analysis," Science and Technology of Nuclear Installations, vol. 2008, Article ID 428168, 18 pages, 2008. 

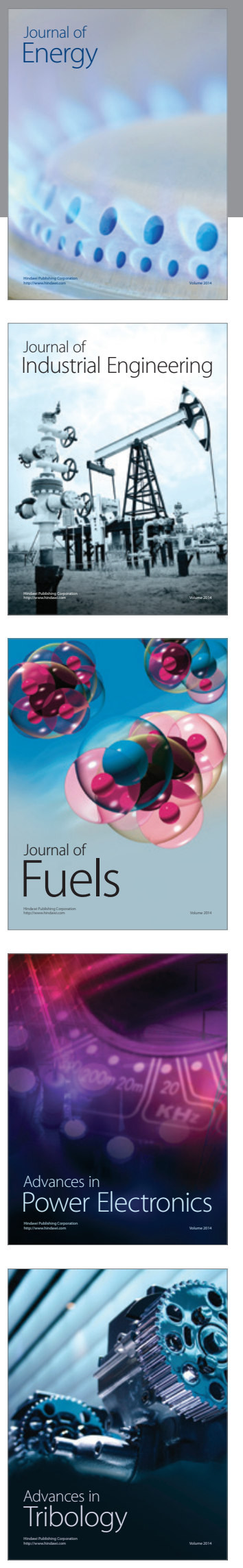
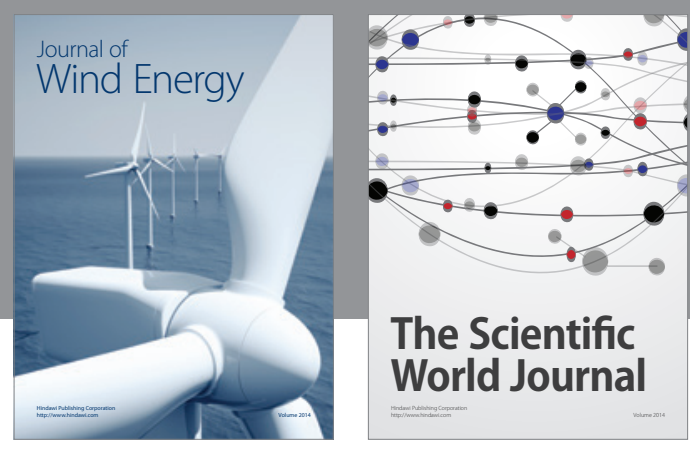

The Scientific World Journal

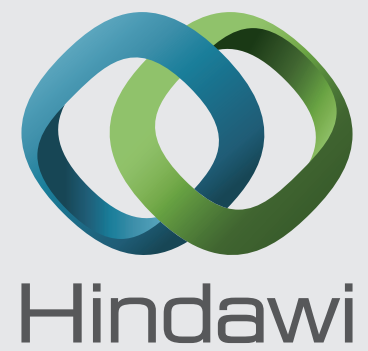

Submit your manuscripts at http://www.hindawi.com
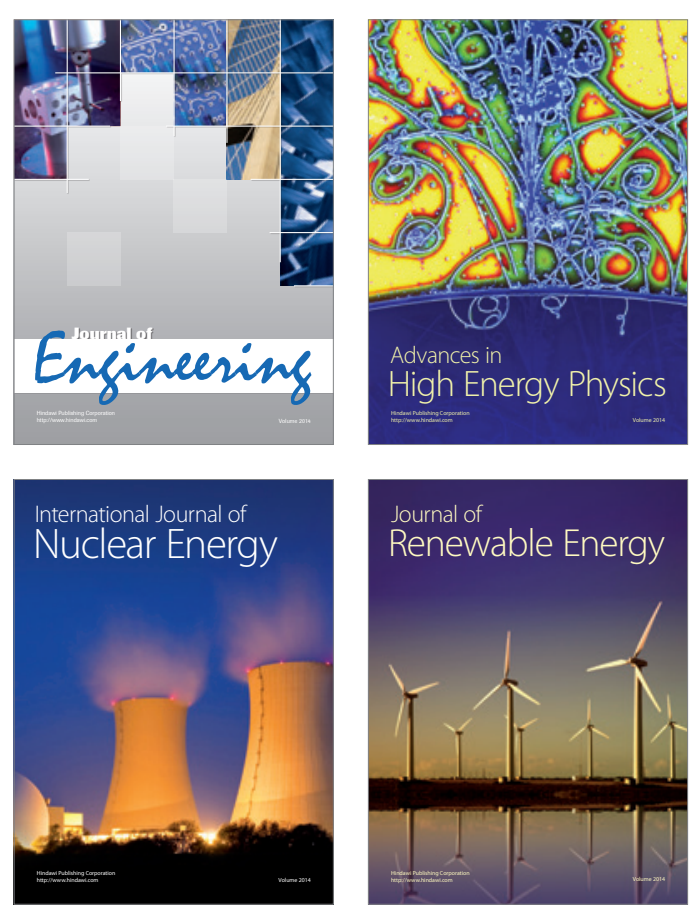

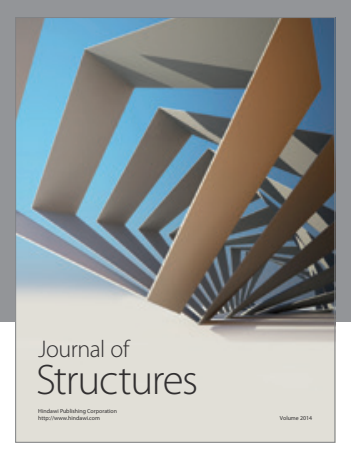

Rotating
Mechinery
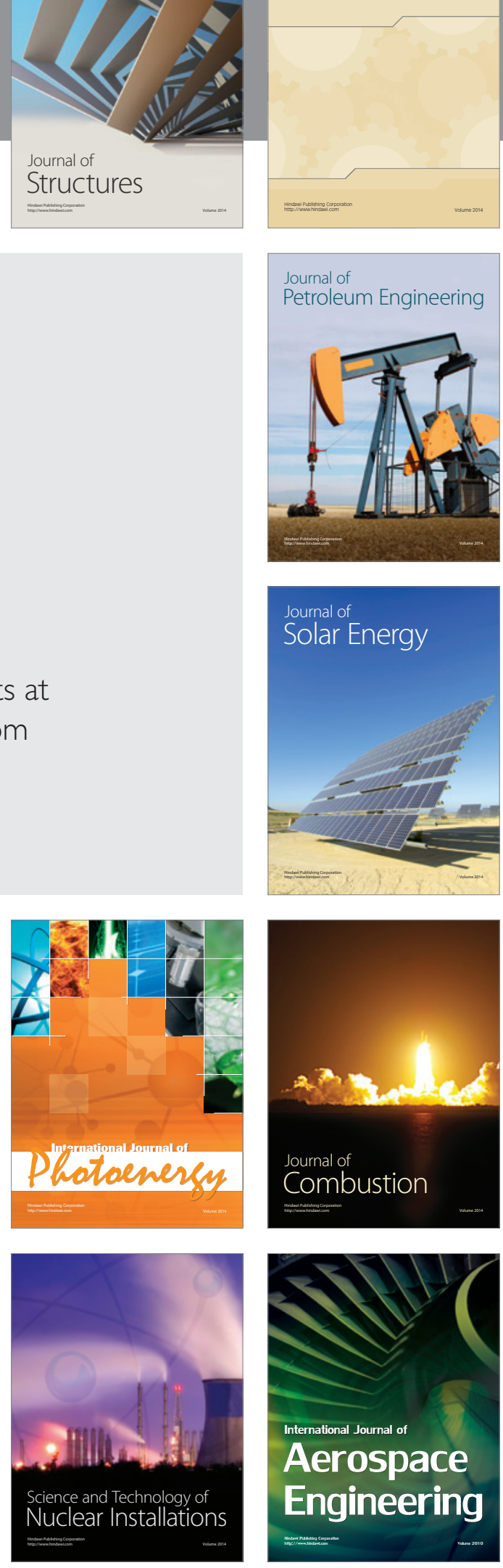